\title{
Incidence and predictors of LTFU among adults with TB/HIV co-infection in two governmental hospitals, Mekelle, Ethiopia, 2009-2016: survival model approach
}

Kebede Embaye Gezae* (D), Haftom Temesgen Abebe and Letekirstos Gebreegziabher Gebretsadik

\begin{abstract}
Background: Lost to follow-up (LTFU) negatively affects the treatment success of Anti-Retroviral Therapy (ART) and thus, increases Tuberculosis-Human Immunodeficiency Virus (TB/HIV) related morbidity, mortality and hospitalization. However, the incidence and predictors of loss to follow up (LTFU) among adults with TB/HIV co-infection have not yet well-investigated in Ethiopia. Therefore, this study was aimed at investigating the incidence and predictors of LTFU in the study setting in particular.

Methods: A facility based retrospective cohort study was employed among 305 (114 anemic and 191 normal) TB/HIV co-infected adults in two governmental hospitals (Mekelle Hospital and Ayder Comprehensive Specialized Hospital), Mekelle, Ethiopia from 2009 to 2016 and data were collected using checklist. Besides to descriptive statistics, a cox regression analysis was applied to identify statistically significant predictors of LTFU at $5 \%$ level of significance. Eventually, the Adjusted Hazard Ratio (AHR) and 95\% Confidence Interval (Cl) were estimated and interpreted for predictors of LTFU in the final cox model.

Results: Generally, 45 of 305 (14.8\%) of TB/HIV co-infected adults were LTFU with an incidence rate of 4.5 new LTFUs per 100 Person Years (PYs) and a median follow up time of 3.1 years (Interquartile Range (IQR): 0.8-5.3 Years). Hemoglobin level $\leq 11.0 \mathrm{~g} / \mathrm{dl}(\mathrm{AHR}=2.660 ; 95 \% \mathrm{Cl}: 1.459-4.848)$, and any history of $\mathrm{Ol} / \mathrm{s}(\mathrm{AHR}=3.795 ; 95 \% \mathrm{Cl}: 1.165-12.364)$ were risk factors of LTFU. While, adverse drug events ( $\mathrm{AHR}=0.451 ; 95 \% \mathrm{Cl}$ : 0.216-0.941), TB treatment completion (AHR $=0.121 ; 95 \%$ Cl: 0.057-0.254), and being on Isoniazid Preventive Therapy (IPT) (AHR $=0.085 ; 95 \% \mathrm{Cl}$ : 0.012-0.628) had protective effect against LTFU.

Conclusions: One in approximately seven TB/HIV co-infected adults had experienced of LTFU with an incidence rate 4.5 LTFUs per 100 PYs. The LTFU rate was higher among adults with low baseline hemoglobin level, no adverse drug events, presence of Ol/s, failure to complete TB treatment, and being not on IPT. Therefore, it is advisable to treat anemia and active TB, and preventing the occurrence of Ols including TB using IPT to reduce the incidence of LTFU among TB/HIV co-infected adults.
\end{abstract}

Keywords: Adults, Cox model, Hazard ratio, LTFU-TB/HIV

\footnotetext{
* Correspondence: aredom14@gmail.com

Department of Biostatistics, School of Public Health, College of Health

Sciences, Mekelle University, P.O. Box: 1871, Mekelle, Ethiopia
}

(c) The Author(s). 2019 Open Access This article is distributed under the terms of the Creative Commons Attribution 4.0 International License (http://creativecommons.org/licenses/by/4.0/), which permits unrestricted use, distribution, and reproduction in any medium, provided you give appropriate credit to the original author(s) and the source, provide a link to the Creative Commons license, and indicate if changes were made. The Creative Commons Public Domain Dedication waiver (http://creativecommons.org/publicdomain/zero/1.0/) applies to the data made available in this article, unless otherwise stated. 


\section{Background}

From infectious diseases' statistics, Tuberculosis (TB) and Human Immunodeficiency Virus (HIV) are the leading causes of death globally. Despite many efforts have been made to control and prevent the dual occurrences of the diseases, yet TB is the leading cause of mortality and morbidity in People Living with HIV (PLHIV) [1].

Above one third of the world population is infected with Tuberculosis (TB) and 5-10\% of them develop active TB. The reactivation of Latent TB infection (LTBI) to active TB diseases is pronounced among PLHIV by approximately 20 times on average. Globally, approximately one million PLHIV co-infected with TB in 2017. TB is the leading cause of death among PLHIV attributable to 300,000 HIV-associated TB deaths in 2017 in which Africa accounted for the largest shares (84\%). Moreover, PLHIV faces the threat of drug-resistant TB. If diagnosis is delayed there is increased risk of mortality from multi-drug resistant and extensively drug-resistant TB [2].

Studies from SSA have also shown that the cumulative incidence of attrition after 3 years of follow-up can be up to $35 \%$. A declined from $86 \%$ at 6 months to $77 \%$ by 36 months after ART initiation in SSA [3, 4]. Thus, attrition remains a major challenge among adults with HIV and $\mathrm{TB}$ in resource limited setting of Low and Middle Income Countries (LMICs) as a result of scarce data on Lost to Follow-Up (LTFU) [5, 6].

Currently, quality of HIV health care services and Anti-Retroviral Therapy (ART) coverage are significantly increasing from time to time. However, LTFU rate is still high and many people drop out at various phases of the treatment pathway. Because of the reasons why people LTFU are not clearly investigated, a poor adherence to treatment is achieved that results in undesired treatment outcomes [7].

LTFU minimizes the benefits of ART in PLHIV which can enhance the occurrence of Opportunistic Infections $(\mathrm{OI} / \mathrm{s})$ including $\mathrm{TB}$ as a result of immune suppression. Therefore, it intensifies the TB/HIV or Acquired Immune Deficiency Syndrome (AIDS) related negative consequences - morbidity, mortality, and hospitalizations - as a result of dual burdens of the two infections. Moreover, LTFU in HIV or TB/HIV co-infected adults has also adverse consequences such as drug toxicity, treatment failure, and drug resistance that ultimately shorten the survival of patients [8-10].

Different literatures have been shown that LTFU attributes to an increased mortality globally and approximately 1 death every 3 LTFUs (40\%) in the SSA region particularly [11-14]. In addition, many studies in the region identified risk factors associated with increased LTFU are mainly: under-nutrition, reduced baseline CD4 count, co-infection with $\mathrm{OI} / \mathrm{s}$ including active TB, advanced clinical staging, adverse drug reactions, gaps in services, and low access to ART services $[3,13,15,16]$.

Early screening and treatment of $\mathrm{TB}$ are on the other hand important to reduce the dual burdens of TB and HIV, reactivation from Latent TB infection (LTBI) to active TB disease, and prevent the transmissions of HIV and TB. Ethiopia has adopted the World Health Organization (WHO) Stop TB strategy which currently is being used as a guideline for the anti TB treatment regimen in almost all health facilities throughout the country since Directly Observed Therapy Short Course (DOTS) full implementation coverage in 2000. Nationally, however, the utilization was yet restricted to approximately $92 \%$ due to the low health coverage and poor health access [17].

Generally, LTFU is more common in resource poor setting countries as a result of poor adherence and low health care seeking behavior of people. In an ART in LMICs study, the LTFU after 1 year of ART initiation is greater than $40 \%$ that is mainly associated with advanced WHO clinical stage (AIDS) and very low baseline CD4 as a result of late initiation. Though the first 6 months of ART initiation are very important to reduce the LTFU rate, the health care seeking behavior of people remains a major challenge yet to increase retention rate $[18,19]$.

In Ethiopia, ART was begun in 2003 and free ART was launched in 2005. An estimated 739, 000 Ethiopians are currently living with HIV and all of them eligible to initiate ART irrespective of their baseline CD4 cell count. However, the ART coverage is approximately $76 \%$ in adult HIV patients [20]. Despite the high LTFU related negative consequences, little was known even on TB and HIV related LTFU rate in adults in Ethiopia and thus, the incidence and predictors of LTFU are unknown. Thus, this study was aimed at partly filling the gap that will contribute its own role in reducing negative consequences of LTFU among people co-infected with TB and HIV in the country in general and the study setting in particular.

\section{Methods}

\section{Study setting, design and population}

A facility based retrospective cohort study was employed among adults with TB/HIV co-infection who have been initiated ART from 2009 to 2016 at two governmental hospitals (i.e. Mekelle Hospital and Ayder Comprehensive Specialized Hospital), Mekelle, Ethiopia to determine the incidence and predictors of LTFU. Mekelle is the capital city of the national regional state of Tigray which is $783 \mathrm{~km}$ far from Addis Ababa, the capital of Ethiopia.

Moreover, Mekelle Hospital has been begun ART services delivery since September, 2004 and up to now, more than 10,000 HIV patients have been followed their 
ART services. All TB/HIV co-infected patients who have been started ART from January, 2009 to December, 2016 were included in the study for the final analysis. However, TB/HIV patients with unknown ART follow up status and short follow up time (less than 1 month) were excluded from the study.

\section{Sampling method and sample size determination}

In this study, the study subjects were selected from ART registration book based on their TB and HIV status. Furthermore, a minimum sample size was also estimated from previous study that was focused on LTFU conducted in Northern Ethiopia [21] by considering baseline hemoglobin level (anemia status) as an exposure variable (i.e. $<=11.0 \mathrm{~g} / \mathrm{dl}$ (anemic) as exposed and $>11.0 \mathrm{~g} / \mathrm{dl}$ (normal) as non-exposed). We used the formula for sample size calculation in survival data analysis based on the following underlining assumptions: two population proportion $\left(\mathrm{q}_{1}=\right.$ proportion exposed group and $\mathrm{q}_{\mathrm{o}}=$ proportion of non-exposed), $80 \%$ statistical power, $95 \%$ confidence level, and probability of LTFU from the previous study on LTFU. The number of events (LTFUs) needed to keep the optimum statistical power are estimated to be 62 as follows.

$$
\begin{aligned}
& \text { Number of events needed }=\frac{\left(Z_{\alpha / 2}+Z_{\beta}\right)^{2}}{\log (H R)^{2 *} q_{0}{ }^{*} q_{1}}=62 \\
& \text { Where: } Z_{\alpha / 2}=1.96, Z_{\beta}=0.84 \text {, Hazard Ratio } \\
& \frac{\text { Incidence of LTFU among exposed }}{\text { Incidence of LTFU among non exposed }}=0.49 \\
& q_{o}=\text { proportion of non-exposed HIV adults }(>11.0 \mathrm{~g} / \mathrm{dl}) \\
& =57.1 \% \approx 0.57 \\
& q_{1}=\text { proportion of exposed HIV adults }(<=11.0 \mathrm{~g} / \mathrm{dl}) \\
& =42.9 \% \approx 0.43
\end{aligned}
$$

Probability of LTFU $=9.8 \% \approx 0.10$.

However, $305 \mathrm{~TB} / \mathrm{HIV}$ co-infected adults were included retrospectively from January, 2009 to December, 2016 using all consecutive sampling in the study setting.

\section{Data collection and study variables}

A standardized data collection checklist was prepared by the principal investigator to extract data from the ART registration book and patient medical records (charts). Prior to data collection a pilot test was done and thus, the data collection tool was modified accordingly. The checklist consisted of variables registered during ART initiation and follow up are - Sex, Age, Marital Status, Educational Level, Weight (kg), Body Mass Index (kg/ $\mathrm{m}^{2}$ ), Functional Status, WHO clinical stage, Hemoglobin level (g/dl), CD4 Cell Count (cells $/ \mathrm{mm}^{3}$ ), Adverse events (Drug Side Effects), IPT prophylaxis, Co-trimoxazole Prophylactic Therapy (CPT), Opportunistic Infections (OI/s) diagnosis, TB Category, Isoniazid Preventive Therapy (IPT), and TB treatment completion - Four trained data collectors were participated in data collection. In addition, data collectors were supervised and data collection tool (checklist) was assessed for completeness, consistency and accuracy by the principal investigator through daily supervision.

The ART follow up status was recorded as dead, alive, transfer, LTFU, drop out or stop. Patients who missed their ART follow up for at least three consecutive months recorded as LTFU. The event was LTFU and the outcome variable was time to LTFU. Thus, the event of interest (LTFU) was labeled as 1 and 0 else considered as censored.

\section{Statistical data analysis}

First, data were entered, and then exported to STATA version 12.0. Data were cleaned and categorical variables were labeled prior to data analysis and data were also declared to be survival-time data. Survival data analysis was done using cox regression analysis besides to the descriptive statistics. Kaplan Meier (KM) curves were drawn to estimate the probability of LTFU and proportionality hazards assumption was checked for covariates intended to be included in the final cox model. Log rank test was used to select categorical predictors. Decision was based on a $p$-value of 0.25 in univariate analysis for potential candidate variables selection to be considered in the final model. Variables with a p-value of less than $0.05(5 \%)$ were considered as statistically significant predictors of LTFU after interaction effects and model diagnostics checked. Finally, the Adjusted Hazard Ratio and 95\% CI were interpreted for the statistically significant predictors of LTFU in the final cox model.

\section{Results}

Baseline socio demographic characteristics and LTFU rate of adults with TB/HIV co-infection

A total of $305 \mathrm{~TB} / \mathrm{HIV}$ co-infected adults were involved in the study that contributes 944.4 PYs. Above half (51.5\%) of the study subjects were females, and above two -fifth $(42.3 \%)$ of them had also an age above their median (> 35 years), 129 (42.3\%) had married marital status, 119 (39.0\%) had secondary educational status.

Regarding LTFU, 45 of 305 (14.8\%) of adults co-infected with TB/HIV experienced LTFU throughout the entire follow up time and the overall LTFU rate was found to be approximately 4.5 LTFU cases per 100 PYs with a median follow up time of 3.1 years (Interquartile Range (IQR): 0.8-5.3 Years). Moreover, 26 of 45 (57.8\%) of the LTFU cases were experienced among females with an incidence rate of 5.1 new cases per 100 PYs. On the other hand, majority (68.9\%) of the total LTFUs were also seen among adults who had an age above the median (> 35 years) and approximately $89.0 \%$ of the event of interest was observed among orthodox followers (Table 1). 
Table 1 Baseline socio-demographic characteristics and distribution by LTFU status of adults with TB/HIV co-infection in two governmental hospitals, Mekelle, Ethiopia, 2009-2016 ( $n=305)$

\begin{tabular}{|c|c|c|c|c|c|}
\hline $\begin{array}{l}\text { Socio-demographic } \\
\text { characteristics }\end{array}$ & $\begin{array}{l}\text { LTFU }\left(n_{1}=45\right) \\
\text { Frequency }(\%)\end{array}$ & $\begin{array}{l}\text { No-LTFU }\left(n_{2}=260\right) \\
\text { Frequency }(\%)\end{array}$ & $\begin{array}{l}\text { Total }(n=305) \\
\text { Frequency }(\%)\end{array}$ & $\begin{array}{l}\text { LTFU Rate }[95 \% \mathrm{Cl}] \\
\text { Per } 100 \mathrm{PYs}\end{array}$ & $P$-value \\
\hline Sex & & & & & 0.3644 \\
\hline Male & $19(42.2)$ & 129 (49.6) & $148(48.5)$ & $3.9[2.5,6.1]$ & \\
\hline Female & $26(57.8)$ & $131(50.4)$ & $157(51.5)$ & $5.1[3.5,7.5]$ & \\
\hline Age (Years) & & & & & 0.1078 \\
\hline$>35$ & $14(31.1)$ & $115(44.2)$ & $129(42.3)$ & $3.3[1.9,5.5]$ & \\
\hline$\leq 35$ & $31(68.9)$ & 145 (55.8) & $176(57.7)$ & $5.5[3.9,7.8]$ & \\
\hline Marital Status & & & & & 0.3710 \\
\hline Single & $13(28.9)$ & $56(21.6)$ & $69(22.6)$ & $6.2[3.6,10.7]$ & \\
\hline Married & $20(44.4)$ & 109 (41.9) & $129(42.3)$ & $4.5[2.9,7.0]$ & \\
\hline Others $^{\mathrm{a}}$ & $12(26.7)$ & $95(36.5)$ & 107 (35.1) & $3.5[2.0,6.1]$ & \\
\hline Educational Level & & & & & 0.5581 \\
\hline No Education & $10(22.2)$ & $55(21.2)$ & $65(21.3)$ & $4.4[2.4,8.1]$ & \\
\hline Primary & $11(24.4$ & 79 (30.4) & $90(29.5)$ & $3.8[2.1,6.8]$ & \\
\hline Secondary & $21(46.7)$ & $98(37.7)$ & $119(39.0)$ & $5.7[3.7,8.7]$ & \\
\hline Tertiary & $3(6.7)$ & $28(10.8)$ & $31(10.2)$ & $2.8[0.9,8.7]$ & \\
\hline Religion & & & & & 0.0077 \\
\hline Orthodox & 40 (88.9) & 253 (97.3) & $293(96.1)$ & $4.1[3.0,5.6]$ & \\
\hline Muslim & $5(11.1)$ & $7(2.7)$ & $12(3.9)$ & $21.1[8.8,50.8]$ & \\
\hline Health Institution & & & & & 0.6074 \\
\hline Ayder Hospital & $21(46.7)$ & $112(43.1)$ & 133(43.6) & $5.0[3.3,7.7]$ & \\
\hline Mekelle Hospital & $24(52.3)$ & $148(56.9)$ & $172(56.4)$ & $4.2[2.8,6.2]$ & \\
\hline
\end{tabular}

Others ${ }^{\mathrm{a}}$ : Divorced/Widowed/Separated

Baseline clinical characteristics and distribution by LTFU status of adults with TB/HIV co-infection

Based on their baseline clinical characteristics, above half $(51.5 \%)$ of the TB/HIV adults had a baseline BMI above the median $\left(\mathrm{BMI}>17.4 \mathrm{~kg} / \mathrm{m}^{2}\right)$. In addition, 54 of 305 (17.7\%), 142 of 305 (46.6\%), 250 of 305 (82.0\%), and 114 of $305(37.4 \%)$ of adults had baseline: bedridden functional status, clinical stage IV, CD4 cell count ( $<=200$ cells $/ \mathrm{mm}^{3}$ ), and anemic status, respectively.

Based on their LTFU status, $62.2 \%$ of the total LTFU cases were seen in TB/HIV adults with a baseline BMI of $<=17.4 \mathrm{~kg} / \mathrm{m}^{2}$ with an incidence rate of 6.6 new cases per 100 PYs and on the other hand the LTFU rate was 8.5 per 100 PYs among TB/HIV adults with baseline anemic status (Table 2).

Moreover, when we draw KM curve based on baseline hemoglobin level to compare the LTFU estimates - It was higher among the anemic TB/HIV co-infected adults than their normal counter parts (Fig. 1).

\section{Diagnosis and treatment characteristics and distribution} by LTFU status of adults with TB/HIV co-infection

Based on this category, approximately $16.0 \%$ of HIV patients were under IPT during the course of their follow up and $83.3 \%$ were taken CPT as a means to prevent $\mathrm{OI} / \mathrm{s}$. To the contrary, majority (63.0\%) of TB/HIV co-infected adults were not reported any adverse drug events with a LTFU rate of approximately twice those we had been experienced with adverse events (Table 3).

\section{Predictors of LTFU among adults with TB/HIV co-infection in the final cox model}

Five variables became statistically significant in the final cox model: Baseline hemoglobin level $(\mathrm{AHR}=2.660$; 95\% CI: 1.459-4.848), adverse drug events $(\mathrm{AHR}=0.451 ; 95 \% \mathrm{CI}$ : $0.216-0.941)$, history of OI/s (AHR $=3.795$; 95\%CI: $1.165-$ 12.364), TB Treatment Completion $(\mathrm{AHR}=0.121 ; 95 \% \mathrm{CI}$ : $0.057-0.254)$, and being on IPT $(\mathrm{AHR}=0.085$; $95 \% \mathrm{CI}$ : 0.012-0.628). Thus, TB/HIV co-infected patients with anemia status, and presence of at least one OI were approximately 2.66 , and 3.80 times more likely to LTFU than their respective comparative groups, respectively. However, TB/HIV co-infected patients who: reported adverse drug events, completed TB treatment phase, and being on IPT were protected by nearly - 55\%, 88\%, and $92 \%$ - against LTFU than their counter reference categories, respectively (Table 4). 
Table 2 Baseline clinical characteristics and distribution by LTFU status of adults with TB/HIV co-infection in two governmental hospitals, Mekelle, Ethiopia, 2009-2016 ( $n=305)$

\begin{tabular}{|c|c|c|c|c|c|}
\hline $\begin{array}{l}\text { Baseline } \\
\text { characteristics }\end{array}$ & $\begin{array}{l}\text { LTFU }\left(n_{1}=45\right) \\
\text { Frequency }(\%)\end{array}$ & $\begin{array}{l}\text { No-LTFU }\left(n_{2}=260\right) \\
\text { Frequency }(\%)\end{array}$ & $\begin{array}{l}\text { Total }(n=305) \\
\text { Frequency }(\%)\end{array}$ & $\begin{array}{l}\text { LTFU Rate }[95 \% \mathrm{Cl}] \\
\text { Per } 100 \mathrm{PYs}\end{array}$ & $P$-value \\
\hline Body Mass Index $\left(\mathrm{kg} / \mathrm{m}^{2}\right)$ & & & & & 0.0138 \\
\hline$>17.4$ & $17(37.8)$ & $131(50.4)$ & $148(48.5)$ & $3.0[1.8,4.8]$ & \\
\hline$<=17.4$ & $28(62.2)$ & $129(49.6)$ & $157(51.5)$ & $6.6[4.6,9.6]$ & \\
\hline Functional Status & & & & & 0.1476 \\
\hline Working & $17(37.8)$ & $124(47.7)$ & $141(46.2)$ & $3.2[2.0,5.2]$ & \\
\hline Ambulatory & $19(42.2)$ & $91(35.0)$ & $110(36.1)$ & $5.4[3.5,8.5]$ & \\
\hline Bedridden & $9(20.0)$ & $45(17.3)$ & $54(17.7)$ & $7.8[3.4,14.2]$ & \\
\hline Clinical Stage & & & & & 0.1093 \\
\hline | or || & $4(8.9)$ & $28(10.8)$ & $32(10.5)$ & $3.2[1.2,8.6]$ & \\
\hline III & $15(33.3)$ & $116(44.6)$ & $131(42.9)$ & $3.3[2.0,5.4]$ & \\
\hline IV & $26(57.8)$ & $116(44.6)$ & $142(46.6)$ & $6.3[4.3,9.3]$ & \\
\hline CD4 Count (Cells/mm³) & & & & & 0.6213 \\
\hline$>200$ & $8(17.8)$ & $47(18.1)$ & $55(18.0)$ & $3.8[1.9,7.6]$ & \\
\hline$<=200$ & $37(82.2)$ & $213(81.9)$ & $250(82.0)$ & $4.7[3.4,6.5]$ & \\
\hline Hemoglobin level (g/dl) & & & & & 0.0002 \\
\hline Normal (> 11.0) & $19(42.2)$ & $172(66.2)$ & $191(62.6)$ & $2.8[1.8,4.3]$ & \\
\hline Anemic $(<=11.0)$ & $26(57.8)$ & $88(33.8)$ & $114(37.4)$ & $8.5[5.8,12.5]$ & \\
\hline
\end{tabular}

\section{Discussion}

The current study was investigated to determine the incidence and predictors of LTFU among adults with TB/ HIV co-infection in the study setting. Thus, the incidence rate was found to be 4.5 new LTFU cases per 100 PYs with a median follow up time of 3.1 years (IQR: 0.8-
5.3 years). Up on running our final cox model, statistically significant predictors of LTFU are: baseline hemoglobin level, adverse drug events, history of $\mathrm{OI} / \mathrm{s}$, TB treatment completion, and IPT (Table 4).

In the current study, 45 of 305 (14.8\%) TB/HIV co-infected patients developed the event of interest

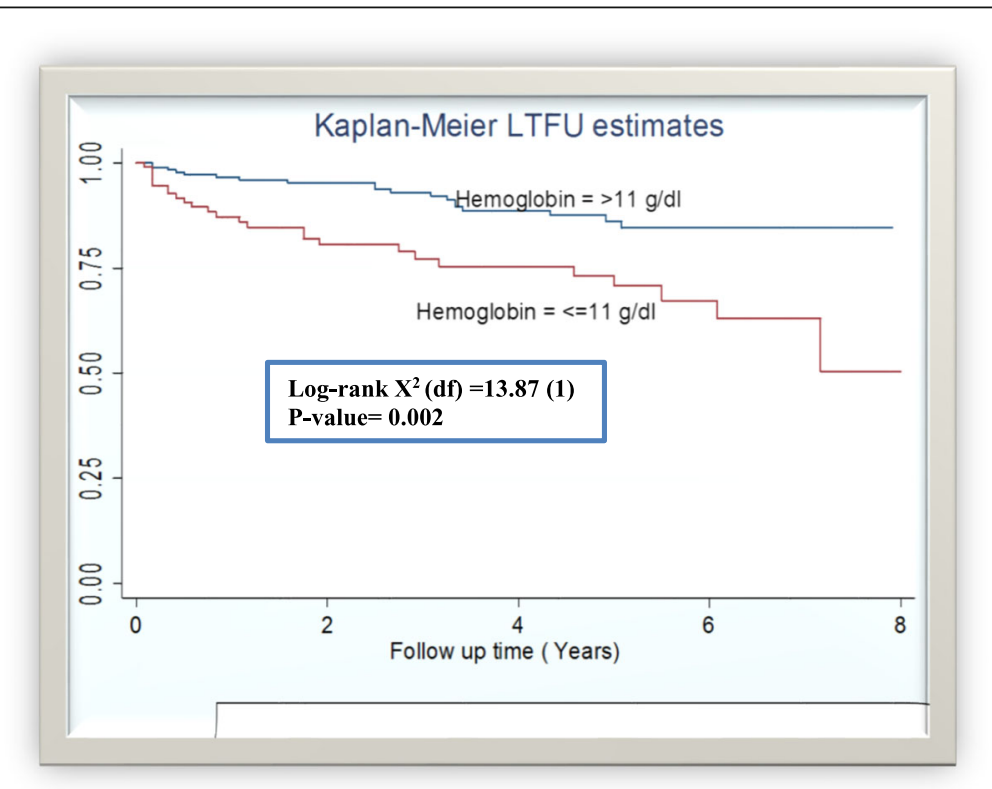

Fig. 1 LTFU estimates of adults with TB/HIV co-infection by baseline hemoglobin level in two governmental hospitals, Mekelle, Ethiopia, 2009-2016 $(n=305)$ 
Table 3 Diagnosis and treatment characteristics and distribution by LTFU status of adults with TB/HIV co-infection in two governmental hospitals, Mekelle, Ethiopia, 2009-2016 ( $n=305)$

\begin{tabular}{|c|c|c|c|c|c|}
\hline $\begin{array}{l}\text { Diagnosis and Treatment } \\
\text { characteristics }\end{array}$ & $\begin{array}{l}\text { LTFU }\left(n_{1}=45\right) \\
\text { Frequency (\%) }\end{array}$ & $\begin{array}{l}\text { No-LTFU }\left(n_{2}=260\right) \\
\text { Frequency }(\%)\end{array}$ & $\begin{array}{l}\text { Total }(n=305) \\
\text { Frequency }(\%)\end{array}$ & $\begin{array}{l}\text { LTFU Rate }[95 \% \mathrm{Cl}] \\
\text { Per } 100 \mathrm{PYs}\end{array}$ & $P$-value \\
\hline Adverse drug events & & & & & 0.0087 \\
\hline No & $39(86.7)$ & $156(60.0)$ & $192(63.0)$ & $6.0[4.4,8.4]$ & \\
\hline Yes & $6(13.3)$ & $104(40.0)$ & $113(37.0)$ & $3.3[1.2,4.3]$ & \\
\hline History Ol/s & & & & & 0.0180 \\
\hline No & $3(6.7)$ & $59(22.7)$ & $62(20.3)$ & $1.4[0.5,4.5]$ & \\
\hline Yes & $42(93.3)$ & $201(77.3)$ & $243(79.7)$ & $5.3[3.9,7.2]$ & \\
\hline TB Category & & & & & 0.0530 \\
\hline PTB & $16(35.6)$ & $116(44.6)$ & $132(43.3)$ & $3.1[1.9,5.1]$ & \\
\hline EPTB/Mixed & $29(64.4)$ & $144(55.4)$ & $173(56.7)$ & $6.0[4.2,8.7]$ & \\
\hline TB treatment completion & & & & & $<0.001$ \\
\hline No & $13(28.9)$ & $39(15.0)$ & $52(17.0)$ & $35.7[20.7,61.5]$ & \\
\hline Yes & $32(71.1)$ & $221(85.0)$ & $253(83.0)$ & $3.3[2.4,4.7]$ & \\
\hline IPT & & & & & 0.0025 \\
\hline on & $1(2.2)$ & $47(18.1)$ & $48(15.7)$ & $5.6[4.2,7.6]$ & \\
\hline off & $44(97.8)$ & $213(81.9)$ & $257(84.3)$ & $0.5[0.1,3.3]$ & \\
\hline CPT & & & & & 0.9189 \\
\hline Off & $7(15.6)$ & $44(16.9)$ & $51(16.7)$ & $4.7[2.2,9.8]$ & \\
\hline On & 38 (84.4) & 216 (83.1) & 254 (83.3) & $4.5[3.3,6.2]$ & \\
\hline
\end{tabular}

OI/s opportunistic Infection/s, PTB Pulmonary Tuberculosis, EPTB Extra Pulmonary Tuberculosis, CPT Co-trimoxazole Prophylactic Therapy, IPT Isoniazid Preventive Therapy

Table 4 Statistically significant predictors of LTFU among adults with TB/HIV co-infection in two governmental hospitals, Mekelle, Ethiopia, 2009-2016 ( $n=305)$

\begin{tabular}{|c|c|c|c|}
\hline Variables & CHR $([95 \% \mathrm{Cl})$ & AHR $[95 \% \mathrm{Cl}]$ & $P$-Value \\
\hline \multicolumn{4}{|l|}{ Hemoglobin } \\
\hline$>11$ (Normal) & 1.000 & 1.000 & \\
\hline$\leq 11$ (Anemic) & $2.928[1.617,5.304]$ & $2.660[1.459,4.848]$ & $0.001^{* *}$ \\
\hline \multicolumn{4}{|c|}{ Adverse drug events } \\
\hline No & 1.000 & 1.000 & \\
\hline Yes & $0.390[0.188,0.811]$ & $0.451[0.216,0.941]$ & $0.034^{*}$ \\
\hline \multicolumn{4}{|l|}{ History of Ol } \\
\hline No & 1.000 & 1.000 & \\
\hline Yes & $3.720[1.153,12.008]$ & $3.795[1.165,12.364]$ & $0.027^{*}$ \\
\hline \multicolumn{4}{|c|}{ TB Treatment Completion } \\
\hline No & 1.000 & 1.000 & \\
\hline Yes & $0.121[0.060,0.244]$ & $0.121[0.057,0.254]$ & $<0.001^{* *}$ \\
\hline \multicolumn{4}{|l|}{ IPT } \\
\hline Off & 1.000 & 1.000 & \\
\hline On & $0.089[0.012,0.645]$ & $0.085[0.012,0.628]$ & $0.016^{*}$ \\
\hline
\end{tabular}

1.000: Reference Category: CHR Crude Hazard Ratio, AHR Adjusted Hazard Ratio, Cl Confidence interval

"Significant at $5 \%$ level of significance, ${ }^{* *}$ significant at $0.1 \%$ level of significance (a) 
(LTFU). The incidence rate was found to be 4.5 per 100 PYs collectively among TB/HIV co-infected adults. The incidence of LTFU was lower as compared to other studies conducted in India, Vietnam, South Africa (Johannesburg), and SSA region $[3,11,22,23]$. To the contrary, the LTFU rate was higher as compared to other studies conducted in Vietnam, South Africa, Cameroon, Zambia, and Liberia [24-28]. However, the LTFU rate is similar to a prospective study conducted in Ethiopia [29]. The high incidence rate in the current study may be due to the duel burden of TB and HIV might be triggered the risk of LTFU as compared to the majority of other studies in which their study subjects were HIV or TB patients alone. Thus, this finding strengthens the idea that LTFU remains a major challenge among adults with TB and HIV in resource limited setting of LMICs such as Ethiopia as a result of scarce data $[5,6]$ and retention of patients in care remains a major challenge to the health care providers and program mangers $[18,19]$.

In this study, LTFU was significantly affected by the baseline hemoglobin level where the incidence of LTFU is roughly twice among the anemic groups than their normal counterpart (AHR $=2.660 ; 95 \% \mathrm{CI}$ : 1.459-4.848). Finding of the current study is consistent with a study conducted in Myanmar, India though that has estimated Odds Ratio (OR) instead of HR and the study subjects were HIV patients than TB/HIV co-infected [30]. However, another study that has been done in Central Tigray, Ethiopia reported the non-predictive effect of baseline hemoglobin to LTFU among HIV Patients under ART [21]. In fact, multiple medications for TB, HIV and Anemia as well may lead to LTFU of the patient from ART follow up due to multiple burdens.

Moreover, patients who have been reported any adverse drug events during the course of their treatment were experienced low risk of LTFU $(A H R=0.451 ; 95 \%$ CI: 0.216-0.941). Though literatures on this study variable were scarce, a facility based case control study has been revealed that presence of drug side effect among HIV/AIDS patient was significant risk factor of LTFU in which patients with adverse drug side effect had approximately 12 times the odds of developing LTFU than those in the control group [31]. The unusual findings observed in this study can be seen from the side that the high health care seeking behavior of the patients may contribute for high adherence to treatment and thus, they might report adverse events if they were experienced which in turn leads to replacement by the safest medication by their doctors' that may tend to decrease the LTFU rate. On the other hand, patients who did not report any drug side effects might be negligent about the adverse effects irrespective of the consequences of LTFU such as morbidity, hospitalization and eventually death.
Moreover, the degree of Scaling up LTBI treatment using IPT was higher among those with adverse drug events that could possibly both increase adherence and decrease LTFU related mortality among adults (18.6\% IPT coverage among those with adverse events as compared to $14.1 \%$ among those did not report it).

Any history of OI/s was also statistically positively associated with LTFU among TB/HIV co-infected adults. Controlling the effect of other predictors, TB/HIV adults who have been diagnosed with at least one OI during the course of their treatment were approximately 4 times more likely to experience LTFU than those who did not (Table 4). It is possibly justifiable that the multiple burdens of diseases may affect the psychological curability and diminish the immune status of the patient and eventually which may result in LTFU from their regular course of treatment.

Successfully completing TB treatment had also a protective effect over LTFU among TB/HIV co-infected adults $(\mathrm{AHR}=0.121 ; 95 \% \mathrm{CI}: 0.057-0.254)$. It is evidenced that both TB and HIV have bidirectional and synergistic relation-ships and thus, the presence of either infection has its own significant contribution for the occurrence of other. The strong association between the two infections will be broken up on the successful completion of TB treatment that may reduce the dual burdens proportionally through TB treatment success rate. Therefore, the health status would be improved, and the incidence of LTFU on the other hand will be decreased as a result of treatment success for TB.

In the current study, majority $(84.3 \%)$ of the patients were off IPT prophylaxis (Table 3 ). Regarding the statistical association, on IPT adults had low risk of LTFU than those of off IPT one (Table 4). The finding of the current study is consistent with a facility based retrospective cohort and follow up studies, and another case control study conducted in Mizan Aman, Southern Ethiopia, and Wukro (all in Ethiopia), respectively that have been revealed all off IPT is a potential risk factor of LTFU among HIV patients [31-33]. This could be related to preventing LTBI reactivation by IPT is simpler than treating active $\mathrm{TB}$ disease using full regiment of TB treatment so that people tend to LTFU as a result of dual burdens of both diseases and dual follow ups as well.

The cause and effect relationship of TB and HIV (was TB or HIV come first) is in fact unclear and considered as TB/HIV co-infected regardless of their temporal relationship. Literatures are also scarce and majority of the literatures are LTFU about HIV patients than TB/HIV co-infected. Moreover, some HIV adults who were on IPT initially tend to develop active TB and thus, started anti TB regimen that may mislead to that IPT was given to active TB co-infected adults. 


\section{Conclusions}

Overall, 1 in approximately seven of TB/HIV co-infected adults had experienced of LTFU with an incidence rate 4.5 LTFUs per 100 PYs. TB/HIV co-infected adults diagnosed with anemia at base line, and diagnosed with any $\mathrm{OI} / \mathrm{s}$ have been strengthened the occurrence of LTFU. Conversely, being on IPT, Completing TB treatment, and developing adverse drug events had protective effect against LTFU among TB/HIV co-infected adults. Therefore, it is advisable to treat anemia and active TB, and preventing the occurrence of OIs including reactivation of latent TB using IPT to reduce the incidence of LTFU among TB/HIV co-infected adults.

\section{Abbreviations \\ AHR: Adjusted Hazard Ratio; AIDS: Acquired Immunodeficiency Virus; ART: Anti- Retroviral Treatment; Cl: Confidence Interval; CPT: Co-trimoxazole Prophylactic Therapy; DOTS: Directly Observed Therapy Short-course; HIV: Human Immunodeficiency Virus; IPT: Isoniazid Preventive Therapy; IQR: Interquartile Range; KM: Kaplan Meier; LMIC: Low and Middle Income Countries; LTBI: Latent Tuberculosis Infection; LTFU: Lost to Follow-up; Ol: Opportunistic Infection; PYs: Person Years; SSA: Sub Saharan Africa; WHO: World Health Organization}

\section{Acknowledgements}

We are thankful to Mekelle University-College of Health Sciences, Mekelle Hospital, and Ayder Comprehensive Specialized Hospital for allowing us to conduct the research.

\section{Funding}

Not applicable.

\section{Availability of data and materials}

The datasets used and/or analyzed during the current study are available from the corresponding author up on reasonable request.

\section{Authors' contributions}

KEG participated in proposing, designing, analyzing data, writing up final report, and drafting the manuscript and thus, acts as the principal investigator of the study. HTA and LGG assisted in proposing, designing, analysis, and writing up the report (supervisors of the study). All authors have read and approved the final manuscript.

\section{Ethics approval and consent to participate}

Ethics approval was issued by the Research Ethics Review Committee (RERC) of Mekelle University-College of Health Sciences and the consent to participate was waived since an already existing data were used. However, confidentiality was assured. Neither the raw data nor the processed data were used for any other purposes other than this study.

\section{Consent for publication}

Not applicable.

\section{Competing interests}

The authors declare that they have no competing interests.

\section{Publisher's Note}

Springer Nature remains neutral with regard to jurisdictional claims in published maps and institutional affiliations.

Received: 8 October 2018 Accepted: 29 January 2019

Published online: 04 February 2019

\section{References}

1. Floyd K, Glaziou P, Zumla A, Raviglione M. The global tuberculosis epidemic and progress in care, prevention, and research: an overview in year 3 of the end TB era. Lancet Respir Med. 2018;6(4):299-314.
2. World Health Organization. Global tuberculosis report 2018. Geneva: World Health Organization; 2018.

3. Alvarez-Uria G, Naik PK, Pakam R, Midde M. Factors associated with attrition, mortality, and loss to follow up after antiretroviral therapy initiation: data from an HIV cohort study in India. Glob Health Action. 2013;6(1):21682.

4. Mutasa-Apollo T, Shiraishi RW, Takarinda KC, Dzangare J, Mugurungi O, Murungu J, Abdul-Quader A, Woodfill CJ. Patient retention, clinical outcomes and attrition-associated factors of HIV-infected patients enrolled in Zimbabwe's National Antiretroviral Therapy Programme, 2007-2010. PLoS One. 2014:9(1):e86305.

5. Alvarez-Uria G, Midde M, Pakam R, Naik PK. Predictors of attrition in patients ineligible for antiretroviral therapy after being diagnosed with HIV: data from an HIV cohort study in India. Biomed Res Int. 2013;2013.

6. Massavon W, Lundin R, Costenaro P, Penazzato M, Namisi PC, Ingabire R, Giaquinto C. Attrition and loss to follow-up among children and adolescents in a community home-based care HIV programme in Uganda. Pediat Therapeut. 2013;3(183):2161-0665.

7. Weiler G. Global update on HIV treatment 2013: results, impact and opportunities, vol. 14. Geneva: World Health Organization; 2013. p. 2017.

8. Kaplan JE, Hanson D, Dworkin MS, Frederick T, Bertolli J, Lindegren ML, Holmberg S, Jones JL. Epidemiology of human immunodeficiency virusassociated opportunistic infections in the United States in the era of highly active antiretroviral therapy. Clin Infect Dis. 2000;30(Supplement 1):S5-14.

9. Low-Beer S, Yip B, O'shaughnessy MV, Hogg RS, Montaner JS. Adherence to triple therapy and viral load response. J Acquir Immune Defic Syndr. 2000; 23(4):360-1

10. Taiwo B. Understanding transmitted HIV resistance through the experience in the USA. Int J Infect Dis. 2009;13(5):552-9.

11. Dalal RP, MacPhail C, Mahayi M, Wing J, Feldman C, Chersich MF, Venter WD. Characteristics and outcomes of adult patients lost to follow-up at an antiretroviral treatment clinic in Johannesburg, South Africa. J Acquir Immune Defic Syndr. 2008:47(1):101-7.

12. Bygrave $H$, Kranzer K, Hilderbrand K, Whittall J, Jouquet G, Goemaere E, Vlahakis N, Triviño L, Makakole L, Ford N. Trends in loss to follow-up among migrant workers on antiretroviral therapy in a community cohort in Lesotho. PLoS One. 2010:5(10):e13198.

13. Brinkhof MW, Pujades-Rodriguez M, Egger M. Mortality of patients lost to follow-up in antiretroviral treatment programmes in resource-limited settings: systematic review and meta-analysis. PLoS One. 2009;4(6):e579.

14. Fatti G, Meintjes G, Shea J, Eley B, Grimwood A. Improved survival and antiretroviral treatment outcomes in adults receiving community-based adherence support: 5-year results from a multicentre cohort study in South Africa. J Acquir Immune Defic Syndr. 2012;61(4):e50-8.

15. Amuron B, Namara G, Birungi J, Nabiryo C, Levin J, Grosskurth $H_{\text {, Coutinho }}$ A, Jaffar S. Mortality and loss-to-follow-up during the pre-treatment period in an antiretroviral therapy programme under normal health service conditions in Uganda. BMC Public Health. 2009:9(1):290.

16. Lanoy E, Mary-Krause M, Tattevin P, Dray-Spira R, Duvivier C, Fischer P, Obadia Y, Lert F, Costagliola D. Predictors identified for losses to follow-up among HIV-seropositive patients. J Clin Epidemiol. 2006;59(8):829-35.

17. Shaweno D, Worku A. Tuberculosis treatment survival of HIV positive TB patients on directly observed treatment short-course in southern Ethiopia: a retrospective cohort study. BMC Res Notes. 2012;5(1):682.

18. Schöni-Affolter F, Keiser O, Mwango A, Stringer J, Ledergerber B, Mulenga L, Bucher HC, Westfall AO, Calmy A, Boulle A, Chintu N. Estimating loss to follow-up in HIV-infected patients on antiretroviral therapy: the effect of the competing risk of death in Zambia and Switzerland. PLoS One. 2011;6(12):e27919.

19. Assefa Y, Kiflie A, Tesfaye D, Mariam DH, Kloos H, Edwin W, Laga M, Van Damme W. Outcomes of antiretroviral treatment program in Ethiopia: retention of patients in care is a major challenge and varies across health facilities. BMC Health Serv Res. 2011;11(1):81

20. Ababa A. Ethiopia and ICF International Calverton. Maryland. 2012;2012.

21. Tadesse $\mathrm{K}$, Fisiha H. Predictors of loss to follow up of patients enrolled on antiretroviral therapy: a retrospective cohort study. J AIDS Clin Res. 2014; 5(393):2.

22. Egger M, Spycher BD, Sidle J, Weigel R, Geng EH, Fox MP, MacPhail P, van Cutsem G, Messou E, Wood R, Nash D. Correcting mortality for loss to follow-up: a nomogram applied to antiretroviral treatment programmes in sub-Saharan Africa. PLoS Med. 2011;8(1):e1000390.

23. Tran DA, Ngo AD, Shakeshaft A, Wilson DP, Doran C, Zhang L. Trends in and determinants of loss to follow up and early mortality in a rapid expansion 
of the antiretroviral treatment program in Vietnam: findings from 13 outpatient clinics. PLoS One. 2013;8(9):e73181.

24. Agbor AA, Bigna JJ, Billong SC, Tejiokem MC, Ekali GL, Plottel CS, Noubiap JJ, Abessolo H, Toby R, Koulla-Shiro S. Factors associated with death during tuberculosis treatment of patients co-infected with HIV at the Yaoundé central hospital, Cameroon: an 8-year hospital-based retrospective cohort study (2006-2013). PLoS One. 2014;9(12):e115211.

25. Mutembo S, Mutanga JN, Musokotwane K, Alisheke L, Whalen CC. Antiretroviral therapy improves survival among TB-HIV co-infected patients who have CD4+ T-cell count above 350cells/mm 3. BMC Infect Dis. 2016; 16(1):572.

26. Yende-Zuma N, Naidoo K. The effect of timing of initiation of ART on loss to follow up in HIV-TB co infected patients in South Africa: an open label randomized controlled trial. J Acquir Immune Defic Syndr (1999). 2016;72(4):430

27. Matsumoto S, Tanuma J, Mizushima D, Nguyen NC, Pham TT, Do CD, Nguyen TQ, Nguyen DT, Nguyen HD, Nguyen LT, Van Nguyen K. High treatment retention rate in HIV-infected patients receiving antiretroviral therapy at two large HIV clinics in Hanoi, Vietnam. PLoS One. 2015;10(9): e0139594.

28. Rogers JH, Jabateh L, Beste J, Wagenaar BH, McBain R, Palazuelos D, Wickett E, Oswald C, Napier HG, Toomey-Garbo J. Impact of community-based adherence support on treatment outcomes for tuberculosis, leprosy and HIV/AIDS-infected individuals in post-Ebola Liberia. Glob Health Action. 2018;11(1):1522150.

29. Telele NF, Kalu AW, Marrone G, Gebre-Selassie S, Fekade D, Tegbaru B, Sönnerborg A. Baseline predictors of antiretroviral treatment failure and lost to follow up in a multicenter countrywide HIV-1 cohort study in Ethiopia. PLoS One. 2018 Jul 11;13(7):e0200505.

30. Thida A, Tun ST, Zaw SK, Lover AA, Cavailler P, Chunn J, Aye MM, Par P, Naing KW, Zan KN, Shwe M. Retention and risk factors for attrition in a large public health ART program in Myanmar: a retrospective cohort analysis. PLoS One. 2014;9(9):e108615.

31. Dessalegn M, Tsadik M, Lemma H. Predictors of lost to follow up to antiretroviral therapy in primary public hospital of Wukro, Tigray, Ethiopia: a case control study. J AIDS HIV Res. 2015;7(1):1-9.

32. Berheto TM, Haile DB, Mohammed S. Predictors of loss to follow-up in patients living with HIV/AIDS after initiation of antiretroviral therapy. N Am J Med Sci. 2014;6(9):453.

33. Teshome W, Belayneh M, Moges M, Mekonnen E, Endrias M, Ayele S, Misganaw T, Shiferaw M, Tesema T. Do loss to follow-up and death rates from ART care vary across primary health care facilities and hospitals in South Ethiopia? A retrospective follow-up study. HIV/AIDS (Auckl). 2015;7:167.

Ready to submit your research? Choose BMC and benefit from:

- fast, convenient online submission

- thorough peer review by experienced researchers in your field

- rapid publication on acceptance

- support for research data, including large and complex data types

- gold Open Access which fosters wider collaboration and increased citations

- maximum visibility for your research: over $100 \mathrm{M}$ website views per year

At BMC, research is always in progress.

Learn more biomedcentral.com/submissions 